Editorial

\title{
Como el COVID-19 pandemia afecta nuestra actividad como cirujanos traumatólogos
}

\section{David Figueroa P. ${ }^{1}$}

1 Editor de la Revista RCHOT, Clínica Alemana de Santiago SA,
Vitacura, Región Metropolitana, Chile

Rev Chil Ortop Traumatol 2020;61:1.

“..... y no hay más cirujanos, urólogos, traumatólogos, solo somos médicos que de repente forman parte de un solo equipo para enfrentar este tsunami que nos ha abrumado...." Dr. Daniele Macchine, Bérgamo, Italia, 9 Marzo 2020.

En estas fechas, lanzando el primer volumen de nuestra revista RCHOT, no podemos estar ajenos a la realidad que vive el mundo con la Pandemia de COVID-19, manifestando algunas reflexiones al respecto.

Como médicos sabemos que se trata de una situación sin precedentes y además inédita en nuestra historia actual. Representa un conjunto de variables que cambian y evolucionan de manera muy rápida, y presiona los sistemas de salud, obligando a tomar decisiones difíciles en nuestro diario quehacer como traumatólogos, como suspender atenciones médicas ambulatorias y electivas, y mantener cuarentenas para evitar diseminación rápida de la enfermedad.

Como médicos tenemos una responsabilidad general en relación al Coronavirus y su prevención y diseminación y debemos actuar en relación a las directrices generales.

También tenemos una responsabilidad más específica para asegurar que el trauma general de urgencia tenga una atención oportuna evitando sobrecargar el sistema de salud.

Puede parecer que la traumatología no está en la primera línea del Coronavirus, pero sin duda nuestro rol es clave en estos momentos, educando, cooperando, asistiendo y dando la atención oportuna de Urgencia al que lo necesita.
Address for correspondence David Figueroa P., MD, PhD Editor Revista RCHOT, Clínica Alemana de Santiago SA, Vitacura, Región Metropolitana, Chile (e-mail: dhfigueroa@gmail.com).
DOI https://doi.org/

10.1055/s-0040-1709723.

ISSN 0716-4548.
Copyright $\odot 2020$ by Thieme Revinter

Publicações Ltda, Rio de Janeiro, Brazil
License terms

(c) (1) $\ominus$ (\$) 